\title{
Prevalence and risk behaviours of camel brucellosis transmission in the peri-urban dairy basin of Niamey, Niger
}

\author{
Harouna MAHAMADOU TANIMOUN ${ }^{1 *}$, Andrée Prisca Ndjoug NDOUR ${ }^{2}$, \\ Haladou GAGARA ${ }^{3}$, Ayayi Justin AKAKPO $^{2}$ and Rianatou BADA-ALAMBEDJI ${ }^{2}$ \\ ${ }^{1}$ Institut National de la Recherche Agronomique du Niger (INRAN), BP 429, Niamey, Niger. \\ ${ }^{2}$ Ecole Inter-Etats des Sciences et Médecine Vétérinaires de Dakar (EISMV), BP 5077, Dakar, Sénégal. \\ ${ }^{3}$ Laboratoire Central de l'Elevage du Niger (LABOCEL), BP 485, Niamey, Niger. \\ ${ }^{*}$ Corresponding author; E-mail: tharounamahamadou@gmail.com; Tel. (+227) $92180147 / 95007444$
}

\begin{tabular}{ccc}
\hline Received: 19-10-2020 & Accepted: 31-03-2021 & Published: 30-04-2021 \\
\hline
\end{tabular}

\begin{abstract}
Considered as one of the most widespread zoonoses in the world and dangerous for human and animal health, brucellosis has been studied mainly in cattle and small ruminants but rarely in camels. The lack of data in Niger on this pathology in camels has aroused particular interest given the breeding method and the dietary habits of urban and peri-urban consumers. It is in this context that we conducted the first cross-sectional study on camel brucellosis in Niger, in the peri-urban dairy basin of Niamey. The general objective of this study was to determine the prevalence of camel brucellosis and the risk behaviours for its transmission at the animal-human interface. Thus, 275 serum samples and 75 camel milk samples were collected from 20 farms in 11 peri-urban localities of Niamey. The serum samples were analysed by 2 methods, namely the Rose Bengal test and indirect ELISA. The overall seroprevalence obtained with the serum samples was 4\%. All 75 milk samples tested by indirect ELISA were negative. In addition, 30 camel farmers were surveyed to assess their knowledge, attitudes, and practices regarding brucellosis. The survey revealed that $96.7 \%$ of the farmers were not aware of brucellosis, the species affected and the modes of transmission. Most of participants stated that camels were in frequent contact with sheep, goats, cattle, and other species. In case of abortion, the placenta and runt are handled with bare hands and sometimes buried or thrown away. All respondents consumed raw camel milk and stated that the milk sold is not pasteurised. These elements constitute risk behaviours for the transmission of this zoonosis and urgent measures should be taken. However, epidemiological investigations must be carried out continuously in order to monitor the evolution of this major zoonosis and to establish an adapted prophylaxis that takes into account this species, in order to protect the herd but also public health.
\end{abstract}

(C) 2021 International Formulae Group. All rights reserved.

Keywords: Camel brucellosis, seroprevalence, lacto-prevalence, KAP study, Niamey-Niger.

\section{INTRODUCTION}

A landlocked country, Niger is a Sahelian country with an essentially agropastoral vocation. Livestock farming plays an important role in the country's economy. It is practiced by nearly $87 \%$ of the active population either as a main activity or as a secondary activity after agriculture (MEIA, 2008). However, food constraints and diseases such as brucellosis hamper its development. 
Brucellosis is a serious and contagious disease caused by bacteria of the genus Brucella. Affecting humans as well as many domestic and wild animal species, it is considered one of the most widespread zoonoses in the world (Corbel, 2006; Akakpo and Ndour, 2013). This anthropozoonosis is responsible for economic losses in livestock farming in the countries where it occurs, and because it is transmissible to humans, it constitutes a public health threat (Seleem et al., 2010; Vikou et al., 2018). Its presence in dairy farming is of great concern because milk and its derivatives are major sources of contamination and disease propagation (Vikou et al., 2018). The transmission of the infection to humans is mainly through the consumption of raw milk or the handling of runts, thus constituting a nonnegligible risk for the health of consumers and farmers (Adamou Harouna, 2008). Brucellosis has been the subject of studies mainly in cattle and small ruminants but rarely in camels. Reported for decades in African, Near and Middle Eastern countries with high prevalence occurence, camel brucellosis has not received the appropriate attention from scientists as in cattle and small ruminants. It has been reported in all camel-breeding countries except Australia and the incidence seems to be closely related to husbandry practices (Wernery, 2014).

In Niger, data on this disease are exceedingly rare. The few studies carried out in the field on cattle and small ruminants show that the disease is present in all the country's livestock systems (Boukary et al., 2014; Issaka Garba, 2018). However, no study has been conducted on camel brucellosis in Niger. The demand for camel milk has increased in recent years in Niger and particularly in Niamey. More and more camel breeders are moving to the outskirts of the city, either permanently or seasonally, to benefit from better access to inputs and/or markets. However, given the breeding method and the eating habits of urban and peri-urban consumers, there is a health risk for both camels and humans. It is in this context that we considered it useful to conduct this cross-sectional study in the peri-urban dairy basin of Niamey. The objective of this work was to determine the prevalence and risk behaviors of camel brucellosis transmission at the animal-human interface in the peri-urban dairy basin of Niamey.

\section{MATERIALS AND METHODS Period and study area}

This cross-sectional study was conducted from August to December 2018 in Niger, more precisely in the peri-urban area (30-35 km) of Niamey (Figure 1). Located in the western part of the country, on the banks of the Niger River and covering an area of about 12,500 ha, the city of Niamey is divided administratively into 5 communes (commune I, II, III, IV and V). Niamey is experiencing amazingly fast population growth. It currently has a population of nearly one million inhabitants and is projected to have between 2 and 2.5 million by 2025 (Graefe et al., 2008).

\section{Sampling \\ Study design}

This study was conducted in two steps. The first step consisted of the identification of camel farms in each study locality. In the second phase, different camel farms were visited for milk (bulk milk and/or individual) and blood sampling. At the same time, questionnaires were submitted to the breeders in order to collect their knowledge, attitudes and practices on camel brucellosis and to identify the behaviour at risk of transmission at the animal-human interface.

\section{Sample size}

The minimum number of 96 samples was determined according to the formula: $\mathrm{n}=1.96^{2} \times \mathrm{p}$ (1-p) $/ d^{2}$ (Thrusfield, 2007), where $\mathrm{n}$ is the estimated sample size, $\mathrm{d}$ (the absolute precision or margin of error) is $10 \%, \mathrm{p}$ is the estimated or expected prevalence. An estimated prevalence of $50 \%$ has been considered as no studies have been previously 
carried out in camel's brucellosis in Niger at the current state of knowledge.

As we did not have a list of peri-urban camel farms in Niamey, we requested the assistance of the Non-Governmental Organizations (NGOs) based in Niamey, Veterinary without Borders Belgium Niger (VSF/B) and Karkara. They assist us to locate the camel herds in the peri-urban areas of Niamey as well as some shopkeepers selling milk. Thus, given the small number of camel farms in the peri-urban dairy basin of Niamey, we counted the maximum number of periurban camel farms in Niamey. We carried out the investigation following the snowball effect scaling approach, and the maximum number of camel farms was included.

\section{Samples}

The overall camels tested were of local breed. Two types of samples were collected: milk and blood. On each farm, milk (bulk and/or individual) was taken from a labelled 50 $\mathrm{ml}$ sample jar. The latter bore the identification number of the holding. In addition, blood samples were taken from the jugular vein in 5 ml dry "Vacutainer ND" type tubes, after the animal had been properly restrained (lying or standing) with the help of 3 persons. The samples were kept cool in a cooler containing dry ice and then sent to the laboratory the same day, centrifuged (blood) and stored in the freezer at $-20{ }^{\circ} \mathrm{C}$ (sera and milk) until analysis.

\section{Administration of questionnaires}

A semi-structured questionnaire with open and closed-ended questions was designed to assess their knowledge of camel brucellosis and to identify risk behaviours for transmission at the animal-human interface. The questionnaire has been formulated to collect data on (a) socio-demographic aspects of the interviewees, (b) the breeding system and type of livestock, (c) the health status of camel breeding, (d) knowledge of camel brucellosis, (e) exposure behaviour at the animal-human interface and exposure behaviour to milk. The target audience was the camel owners, camel keepers, and camel milk collectors the duration of the face-to-face interview in local languages (Hausa or Zarma) was approximately 10 minutes per respondent.

\section{Sample analysis}

The serum samples were tested in parallel by the Rose Bengal test (RBT) and the indirect ELISA (iELISA) (ID Screen Brucellosis serum indirect Multi-species kit, ID Vet France). The camel milk samples were tested by the indirect ELISA (iELISA) (BRUCELISA M kit, APHA Scientific UK). The different steps of the analysis (iELISA and Rose Bengal) were performed according to the protocol provided in the kits by respective manufacturers.

\section{Statistical and mapping analysis software}

The data collected by all procedures (RBT and iELISA) were carefully recorded in Microsoft Excel 2013 and imported into R software version 3.3.3 for statistical analysis. The Chi-Square test was used to compare the proportions and frequencies of the qualitative variables. p-value was considered statistically significant when it was lower than 0.05 . In addition, the KAP survey data were entered using SPHINX software version 5.1.0.5. The maps, on the other hand, were produced using ArcGIS ${ }^{\circledR}$ version 10 software. 3.

\section{Ethical consideration}

The study was achieved with the authorization of the Niger's Minister of Livestock. The administration of the questionnaires and the milk and blood samples collection were done with the prior consent of the livestock producers. We guaranteed the confidentiality of the information collected during the survey and kept the anonymity of those who delivered it. 


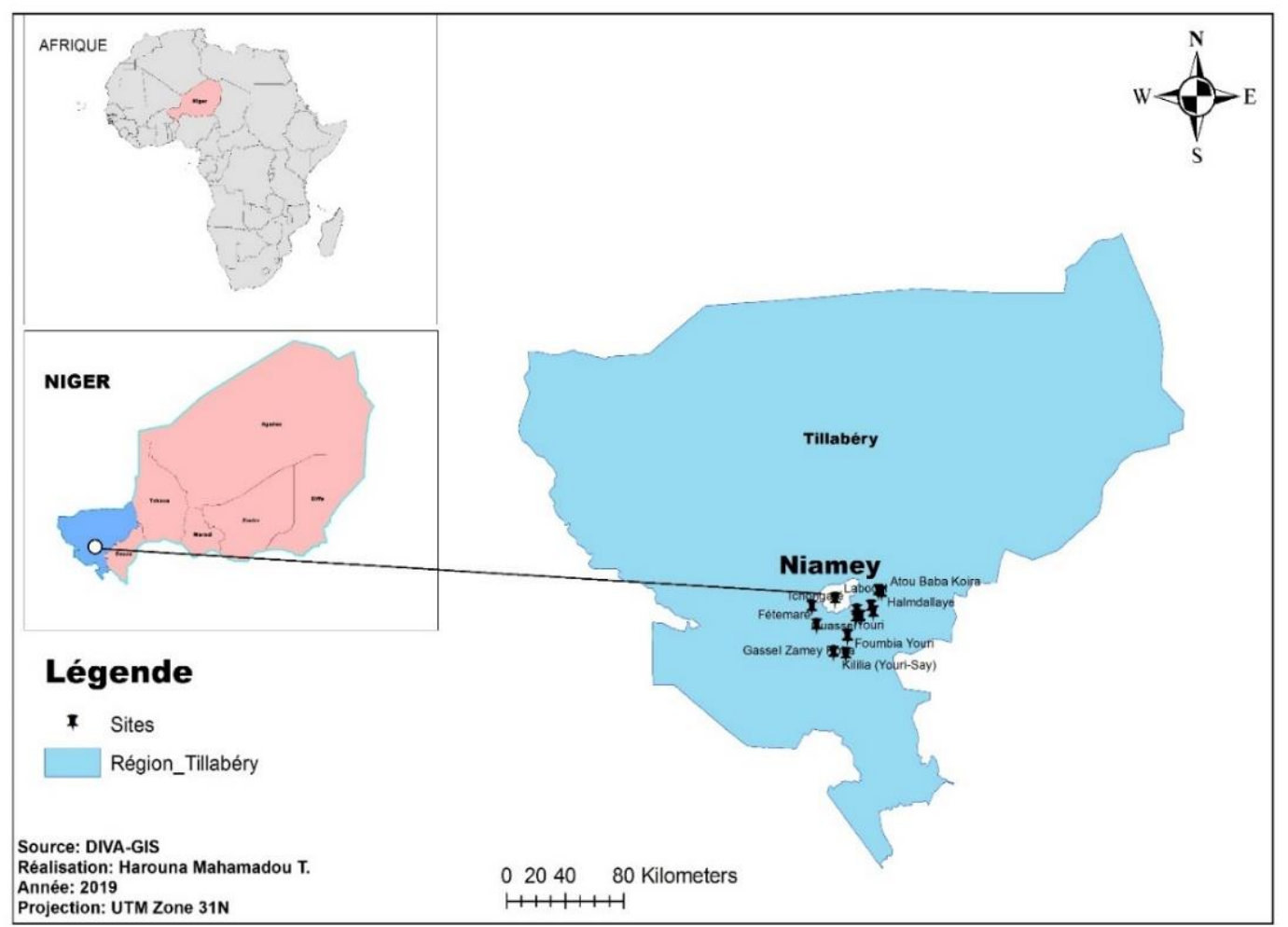

Figure 1: Study area.

\section{RESULTS}

A total of 20 farms in 11 peri-urban localities in Niamey were identified and 275 camels serum samples, including 240 females and 35 males, were tested.

\section{Seroprevalence in the peri-urban dairy basin of Niamey}

Among the 275 serum samples, 11 tested positivesat the iELISA test and 1 at the Rose Bengal test, giving an overall prevalence of $4 \%$ (Table 1 ). The positive sera were all from females. In addition, the Rose Bengal positive serum confirmed by iELISA came from the same herd of Guessel area. The highest prevalences were observed in the locality of Bougoum (16.6\%), Feténamaré $(10.6 \%)$, Soray $(7.69 \%)$ and Foumbia $(6.6 \%)$. On the other hand, in other localities such as Guesselbodi, Fimbiré and Mboda, no positive results were found. However, there is no significant difference between the prevalence among these localities $(\mathrm{p}>0.05)$.
Prevalence on milk samples in the periurban dairy basin of Niamey

All 75 samples of camel milk (20 bulk milk samples and 55 individual milk samples) tested negative by indirect ELISA for an overall prevalence of $0 \%$ in the peri-urban dairy basin of Niamey.

\section{Brucellosis risk behaviours for transmission} at the camel- animals-humans interface Socio-demographic data of participants to the survey

Among the 20 identified farms in 11 peri-urban localities in Niamey, a total of 30 camel farmers agreed to participate in the survey. Most respondents (57\%) were camel keepers, $33 \%$ were owners and $10 \%$ were milk collectors. The survey showed that $47 \%$ of the herders surveyed came from 03 localities, with almost equitable proportions. These are the localities of Guessel (16.67\%), Feténamaré (16.67\%), and Darey bongou (13.33\%). The 
herders who took the least part were those in the localities of Fimbiré and Bougoum (3.33\%).

\section{Breeding system and type of livestock}

The farming method used is traditional semi-intensive farming (100\%). Natural breeding is the only method of reproduction, and milking is only done by hand. The size and composition of the farms varied from five (5) to eighty (80) animals. The bred breeds were mainly local breeds. Most of the farms were owned by single person ( $83.3 \%$ ).

\section{Sanitary situation of camel health status}

According to the farmers interviewed, the diseases present in their herd are mainly skin diseases and parasitic diseases (53.3\%). In all farms surveyed, only $26.7 \%$ vaccinated against pasteurellosis and $16.7 \%$ against smallpox. However, animals were never vaccinated against brucellosis. In 2018, most of respondents $(63 \%)$ did not report abortion; only $22.2 \%$ of the farmers reported five to ten abortions and $14.8 \%$ reported one to five abortions.

\section{Knowledge about camel brucellosis}

Regarding camel brucellosis knowledge, most of the surveyed people knew neither the disease, nor the susceptible animal species, nor the clinical signs of this disease in affected animals, let alone its transmission from animals to humans (Figure 2).

Exposure behaviours at the animal-human interface

Many participants (80\%) said that camels were very often in contact with sheep, goats, cattle, and others animal species. Surveys show that $90 \%$ of the breeders lend and/or borrow a male for breeding purposes; 93.3\% stated that new animals are directly introduced into the herd without any prior quarantine measures. In the event of abortion, most people $(96.7 \%)$ claim that the placenta and the runt are handled with bare hands, sometimes buried or thrown away. All the people surveyed consume raw camel milk and stated that the milk sold is not pasteurized. Most respondents (96.7\%) have never received training on good hygiene practice (milking and milk handling).

Table 1: Positive sera revealed with both serological methods (RBT and iELISA).

\begin{tabular}{lllllll}
\hline Localities & $\begin{array}{l}\text { Number } \\
\text { of farms }\end{array}$ & ELISA & RBT & $\begin{array}{l}\text { Positive } \\
\text { sera }\end{array}$ & $\begin{array}{l}\text { Prevalence } \\
\text { locality (\%) }\end{array}$ & per \\
\hline Darey Bongou & 3 & 1 & 0 & 1 & 3,03 & \\
Guesselbodi & 1 & 0 & 0 & 0 & 0 & \\
Fimbiré & 1 & 0 & 0 & 0 & 0 & \\
Mboda & 1 & 0 & 0 & 0 & 0 & \\
Guessel & 2 & 2 & 1 & 2 & 5,88 & \\
Kililia & 2 & 1 & 0 & 1 & 1,96 & $\mathbf{0 , 5 4 1 2}$ \\
Foumbia & 2 & 1 & 0 & 1 & 6,66 & \\
Soray & 2 & 2 & 0 & 2 & 7,69 & \\
Atou baba koira & 2 & 1 & 0 & 1 & 1,66 & \\
Bougoum & 1 & 1 & 0 & 1 & 16,6 & \\
Feténamaré & 3 & 2 & 0 & 2 & 10,52 & \\
Total & $\mathbf{2 0}$ & $\mathbf{1 1}$ & $\mathbf{1}$ & $\mathbf{1 1}$ & & \\
Prévalence $(\%)$ & - & $\mathbf{4 \%}$ & $\mathbf{0 , 3 6 \%}$ & $\mathbf{4 \%}$ & & \\
\hline
\end{tabular}




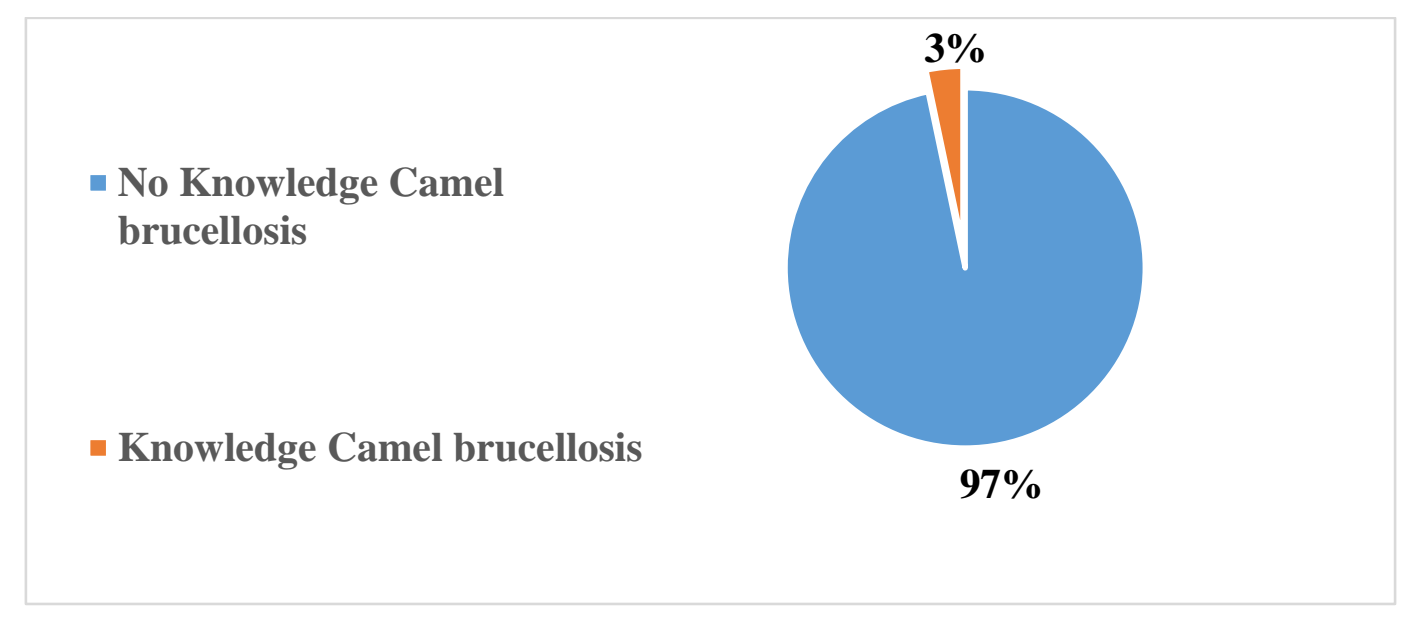

Figure 2: Knowledge about camel brucellosis.

\section{DISCUSSION}

The scarcity of brucellosis investigation in camel is not specific to Niger. In Africa, the main studies recorded were carried in Ethiopia and Libya. It is why our results are mainly compared to those countries. The low seroprevalence in our study $(4 \%)$ is comparable to the $4.1 \%$ seroprevalence recorded in the Afar region in Ethiopia (Hadush et al., 2013), in Libya (Abbas and Agab, 2002). Nevertheless, lowest seroprevalences were recorded in Fafen zone $(1.53 \%)$ in Ethiopia (Robayo and Esubalew, 2017) and in south-eastern (0.9\%) (Gumi et al., 2013) of Ethiopia. However, our result is lower than that obtained by Bekele et al. (2013); Zewolda and Wereta (2012); Teshome et al. (2003) who reported $5.4 \%, 7.6 \%$ and $5.7 \%$ respectively in the Afar region (Ethiopia).

The difference in seroprevalence between these results could be due to differences in the climate of the study areas, sample size, animal management and production systems, and the type of test performed. According to Akakpo and Bornarel (1987), the brucellosis seroprevalence depends on the characteristics of the climate. These authors reported that the tweezers are destroyed in a hot and dry climate, while they are resistant in a hot and humid climate (the climate in the region of Niamey is semi-arid). These authors used other serological techniques namely cELISA, modified Rose
Bengal Test (mRBPT), Complement Fixation Test (CFT) and Serum Agglutination Test (SAT) for the detection of Brucella in Camels. They also performed a combination of serological tests other than the Rose Bengal Test and iELISA. However, none of the serological tests for brucellosis are validated for use in camels as recognized by the OIE (Wernery, 2014). However, it has been found that a combination of different serological tests can increase diagnostic efficiency in camels (Wernery, 2014).

Indeed, the high positivity rate obtained by the ELISA compared to the Rose Bengal test could be explained on one hand by the fact that the Rose Bengal test used is standardized for the detection of antibodies to Brucella abortus in cattle and small ruminants and may therefore not be effective in camels. On the other hand, being a relatively early diagnostic test, it better detects new infections and therefore in an enzootic situation without any real control, the proportion of latent and chronic infections is much higher, and the Rose Bengal Test may be less sensitive (Amona et al., 2016). Furthermore, the indirect Multispecies ELISA kit (ID.Vet France laboratory) used is intended for the detection of antibodies to Brucella abortus, melitensis and suis. This kit has a multi-species conjugate capable of detecting mammalian immunoglobulins, and therefore it could work in camelids although 
we do not have validation data for this species yet.

The zero-prevalence obtained with the milk samples does not exclude the presence of camel brucellosis in this study area, given the epidemiological context (the presence of infection in other species) and the results obtained with sera from animals from the same herds. This could therefore also be linked to the sensibility of BRUCELISA M kit (APHA Scientific UK) used in our study which may not be effective in detecting specific antibodies (anti-Brucella abortus and anti-Brucella melitensis) in camel milk. The camels studied are in majority females $(87.7 \%)$, and all positive sera were from females. According to the literature, males are less sensitive than females to camel brucellosis (Lounes et al., 2010).

From this study, it appears that most of the breeders surveyed had never heard about camel brucellosis. This result contrasts with those reported by Issaka Garba (2018), who found in a survey of bovine brucellosis in and around Niamey where $100 \%$ of the cattle farmers surveyed had already heard about the disease. This difference could be explained by the fact that camel brucellosis has not received adequate attention from the local animal health authorities as in the case of cattle and small ruminants. The lack of awareness campaigns on this disease among camel farmers would justify the poor level of awareness of these farmers regarding the existence of brucellosis in this species.

The farming management of camels is mainly traditional and semi-intensive. Regardless of the production type, camels are very often in contact with sheep, goats, cattle, and other animals. These species are susceptible and sensitive to $B$. abortus and $B$. melitensis, and therefore, close contact between them poses a risk of transmission. To avoid inter-species transmission, different species should be kept separately. However, this is difficult to achieve in a context where animals are taken to pasture. Indeed, the animals go to common pastures with other animal species and drink at the same water points. In these spaces, animals in the locality congregate. The promiscuity between animals from other herds represent a risk of contamination for uninfected animals. Indeed, according to the literature, common pastures and water points are factors in the spread of the disease (Acha and Szyfres, 2005). According to Musa et al. (2008), camels can be infected by $B$. abortus and B. melitensis. The occurrence of brucellosis therefore depends on the Brucella species spread in other animals sharing the same habitat (cross-species transmission) and on the husbandry system. In addition, the lending of males between breeders and the introduction of new animals without quarantine into these herds could be a source of spread of the disease if infected (Musa et al., 2008).

Furthermore, the farmers consume raw camel milk. Milk is recognized as the main source of human contamination in the case of brucellosis (Adamou Harouna, 2008). This would mean that, overall, the zoonotic nature of brucellosis is poorly understood by camel farmers. The fact of handling the placenta and the runt with bare hands in case of abortion is a source of exposure if Brucella are present (Akakpo and Bornarel, 1987). Indeed, humans become contaminated either through direct contact with Brucella animals (this mainly concerns socio-professional categories in contact with animals), or by ingesting raw milk, contaminated fresh cheese, or vegetables soiled by Brucella, animal manure and eaten raw, or by inhaling contaminated air (dust from soiled litter) (Araita, 2013). Hence, these results highlight the urgent need to raise awareness among camel farmers and to involve veterinarians in the conduct of pastoral activities and good hygiene practices.

\section{Conclusion}

The study revealed a seroprevalence of $4 \%$ of brucellosis in camel in the peri-urban area of Niamey in Niger Republic. Regarding the level of infection and the behaviours of herd keepers, adequate measures should be taken as brucellosis is a disease of significant economic and hygienic importance. Farmers must be sensitized and trained in good hygiene practices and the risks related to the 
consumption of raw milk. In addition, appropriate prophylaxis must be introduced which considers this species, in order to protect this livestock population but also public health as the camel milk is more and more consumed by local people. For effective control of this major and neglected zoonosis, the involvement of all stakeholders in animal and human health is necessary as part of a "One Health" approach. Regarding the public health importance of brucellosis, this preliminary study should be followed by others in order to better assess the incidence of infection in the camel population and consumption studies to better assess the importance and risks involved in consuming camel milk. Given the results obtained on brucellosis in animals, studies in human brucellosis should also be considered.

\section{COMPETING INTERESTS}

The authors declare that they have no competing interests.

\section{AUTHORS' CONTRIBUTIONS}

HMT worked on the conceptualization, the data curation, the formal analysis, methodology, writing-original draft, writingreview \& editing. APNN contributed to the methodology, supervision, validation, writingreview \& editing. HG contributed to the data curation, formal analysis, validation. AJA ensured the supervision and the validation of the article. RB-A contributed to the conceptualization, methodology, validation, writing-review \& editing and provided supervision.

\section{ACKNOWLEDGMENTS}

The authors would like to express their gratitude to the regional project to support pastoralism in the Sahel (PRAPS), for funding this research; to the central breeding laboratory of Niger (LABOCEL) for the analysis of samples (serums and milk) and the supply of the complementary kits provided to LABOCEL by the International Atomic Energy Agency (IAEA); To the Veterinary NGOs Veterinary without Borders Belgium Niger (VSF/B), KARKARA for the technical support in the field and to the Zoonoses and
Emerging Livestock Systems (ZELS) Project for the supply of the complement of kits and sampling materials; to the breeders and owners of camels for their frank collaboration.

\section{REFERENCES}

Abbas B, Agab H. 2002. A review of camel brucellosis. Pre. Vet. Med., 55: 47-56. DOI: 10.1016/ S0167-5877(02)00055-7

Acha PN, Szyfres B. 2005. Zoonoses et Maladies Transmissibles Communes à l'Homme et aux Animaux ( (2 ${ }^{2 m e}$ édn). OIE: Paris.

Adamou Harouna H. 2008. Contribution à l'étude épidémiologique de la Brucellose dans les élevages laitiers urbains et périurbains de Niamey (Niger). Thèse, École Inter-États des Sciences et Médecine Vétérinaire (EISMV) DakarSénégal, Dakar-Sénégal, 142 p.

Akakpo AJ, Bornarel P. 1987. Epidémiologie des brucelloses animales en Afrique tropicale: enquêtes clinique, sérologique et bactériologique. Rev. Sci. Tech. Off. Int. Epiz., 6(4): 981-1027. DOI: 10.20506/rst.6.4.313

Akakpo AJ, Ndour APN. 2013. La brucellose bovine en Afrique de l'Ouest et du Centre: état des lieux. Rev. Afr. Santé Prod. Anim., 11: 23-28.

Amona I, Miassangoumouka JP, Banga-mboko $\mathrm{H}$, Adzona PP, Rabeson FA, Ikolakoumou J. 2016. Dépistage sérologique de la brucellose bovine par l'épreuve a l'antigène tamponné (EAT) et l'ELISA dans un centre de multiplication et de métayage bovin en république du Congo-Brazzaville. Journal of Animal \& Plant Sciences, 27(3): 4315-4329.

Araita HH. 2013. Etude Séro-Epidemiologique de la Brucellose animale dans la République de Djibouti. Thèse, École Inter-États des Sciences et Médecine Vétérinaire (EISMV) Dakar-Sénégal, Dakar-Sénégal, $140 \mathrm{p}$.

Bekele WA, Tessema TS, Melaku SK. 2013. Camelus dromedarius brucellosis and its public health associated risks in the Afar National Regional State in northeastern Ethiopia. Acta Veterinaria Scandinavica, 
$55:$

$1-89$.

DOI:

https://doi.org/10.1186/1751-0147-55-89

Boukary AR, Saegerman C, Adehossi E, Matthys F, Vias GF, Yenikoye A, Thys E. 2014. La brucellose en Afrique subsaharienne. Ann. Méd. Vét., 158: 3956.

Corbel MJ. 2006. Brucellosis in humans and animals. WHO, Geneva, 89 p.

Graefe S, Schlecht E, Buerkert A. 2008. Opportunities and challenges of urban and peri-urban agriculture in Niamey, Niger. Outlook on Agriculture, 37(1): 4756. DOI: $10.5367 / 000000008783883564$

Gumi B, Firdessa R, Yamuah L, Sori T, Tolosa T, Aseffa A, Zinsstag J, Schelling E. 2013. Seroprevalence of Brucellosis and Q-Fever in Southeast Ethiopian Pastoral Livestock. Journal of Veterinary Science \& Medical Diagnosis, 2(1): 1-11. DOI: $10.4172 / 2325-9590.1000109$

Hadush A, Pal M, Kassa T, Zeru F. 2013. Seroepidemiology of camel brucellosis in the Afar region of Northeast Ethiopia. J. Vet. Med. Anim. Health, 5(9): 269-275. DOI: 10.5897/JVMAH13.0235

Issaka Garba A. 2018. Brucellose bovine au Niger : enquête cap (connaissances attitudes et pratiques) et prévalence dans les élevages laitiers à Niamey. Thèse, École Inter-États des Sciences et Médecine Vétérinaire (EISMV) DakarSénégal, Dakar-Sénégal, 99 p.

Lounes N, Adaika B, Hamidatou H, Bouyoucef A, Garin-bastuji B. 2010. Enquête préliminaire sur la brucellose cameline dans la région d'El Oued en Algérie. Conference: 4èmes Journées Vétérinaires de Blida.

https://www.researchgate.net/publication $/ 270105043$

Musa MT, Eisa MZ, El Sanousi EM, Abdel Wahab MB, Perrett L. 2008. Brucellosis in camels (Camelus dromedarius) in Darfur, Western Sudan. Journal of
Comparative Pathology, 138(2-3): 151155. DOI: $10.1016 /$ j.jcpa.2007.10.005.

MEIA (Ministère de l'Elevage et des Industries Animales). 2008. Forum National sur la santé animale du 04 au 06 Novembre : Document introductive. MEIA, Niger, 34 p.

Robayo Y, Esubalew S. 2017. Seroprevalence and associated risk factors of brucellosis in camels kept under pastoral management in Fafen zone, Somali regional state, Ethiopia. International Journal of Livestock Research, 7(3): 4956.

DOI: http://dx.doi.org/10.5455/ijlr.201611180 73604

Seleem MN, Boyle SM, Sriranganathan N. 2010. Brucellosis: a re-emerging zoonosis. Veterinary Microbiology, 140 (3-4):

392-398.

DOI: 10.1016/j.vetmic.2009.06.021

Teshome H, Molla B, Tibbo M. 2003. A seroprevalence study of camel brucellosis in three camel-rearing regions of Ethiopia. Trop. Anim. Health Prod., 35: 381-389.

DOI: 10.1023/A:1025874310261

Thrusfield M. 2007. Veterinary Epidemiology ( $3^{\text {rd }}$ edn). Blackwell Science Ltd: Oxford.

Vikou R, Aplogan LG, Ahanhanzo C, BabaMoussa L, Gbangboche AB. 2018. Prévalence de la brucellose et de la tuberculose chez les bovins au Bénin. Int. J. Biol. Chem. Sci., 12(1): 120-128. DOI: https://dx.doi.org/10.4314/ijbcs.v12i1.9

Wernery U. 2014. Camelid brucellosis: a review. Rev. Sci. Tech. Off. Int. Epiz., 33(3): 839-857. DOI: 10.20506/rst.33.3.2322

Zewolda SW, Wereta MH. 2012. Seroprevalence of Brucella infection in camel and its public health significance in selected districts of Afar region, Ethiopia. J. Environ. Occupat. Sci., 1: 91-98. DOI: $10.5455 /$ jeos.20120711034013 